\title{
FABULACIONES EN EQUÍVOCOS BURLESCOS: LA CHRÓNICA DEL MONSTRO IMAGINADO (1615) DE ALONSO DE LEDESMA Y NOVELA CORTA BARROCA
}

\author{
Antonella Gallo \\ Università degli Studi di Verona \\ antonella.gallo@univr.it
}

\begin{abstract}
1 lonso de Ledesma, segoviano (1562-1623), fue apostrofado justamente de «divino» en la Agudeza y arte de ingenio (Gracián 1987: II, 173) por su refinado conceptismo al servicio de la misión pedagógica de la Compañía de Jesús. Una escueta reseña de sus obras ${ }^{1}$ delata su formación escolástica dentro de la Ratio studiorum jesuítica y su estrecha vinculación con la cultura religiosa y emblemática de la época, como ha sido señalado anteriormente por la crítica (D’Ors 1974 y Rodríguez de la Flor 1982)2. Cultivó asimismo la poesía y prosa jocosa profana con igual primor y acierto que su escritura sagrada, como atestiguan un vejamen de tipo universitario «a lo divino» de 1612 (Cara 2001: 178-181) y su Romancero y monstro imaginado (Ledesma 1615), donde se encuentra la
\end{abstract}

\footnotetext{
1 Detallo aquí un listado completo de sus obras, indicando entre paréntesis la fecha de la primera edición: Conceptos espirituales (1602); Segunda parte de los Conceptos espirituales, y morales (1607); Juegos de Noche Buena, moralizados a la vida de Christo, martirio de Santos, y reformación de costumbres, con unas enigmas hechas para honesta recreación (1611); Tercera parte de Conceptos espirituales, con las obras hechas a la Beatificación del glorioso Patriarca Ignacio de Loyola... para el Colegio de la ciudad de Segovia (1612); Epigramas y hieroglificos, a la vida de Christo, festividades de nuestra Señora, excelencias de santos, y grandezas de Segovia (1625). Según Rodríguez de la Flor (1982: 127), en las Fiestas que hizo el insigne Colegio de la Compañía de Jesús de Salamanca a la Beatificación del glorioso Patriarca S. Ignacio de Loyola (Salazar 1610) se incluye un sermón con treinta y tres jeroglíficos de A. de Ledesma, que servirán también para las fiestas de canonización en Segovia en 1612 y formarán parte, ya muy modificados, del último libro publicado por Ledesma en 1625. Existe edición moderna solo de los Conceptos espirituales y morales (Ledesma 1969 y 1978). La crítica lo ha dado, además, como plausible autor del falso Quijote de Avellaneda (Vindel 1941).

2 Rodríguez de la Flor reseña otra bibliografía sobre el autor (1982: 123, n. 16).
} 
obra que nos ocupa hoy, es decir, la Chrónica del monstro imaginado3. El relato, en equívocos burlescos, se presenta en forma de «librillo de tripera», con su portada disparatada y su «prólogo de burlas», firmado por «lo que tú quisieres», donde se declara que la crónica fue compuesta por «Marcos de Ventanas», aunque luego en el colofón se haga constar que se trata de una traducción en castellano de un libro hallado en lengua siria ${ }^{4}$. El libro/relato se compone de siete capítulos, rematados por unas redondillas compuestas por el monstruo imaginado; en los varios «capítulos de provincia» se narran el nacimiento, compostura y crianza del monstruo (cap. I); se describen su casamiento con «Doña Clara de un huevo» (f. 176v) y las ricas galas de los novios (cap. II); los magníficos banquetes que hubo en la boda a lo largo de tres días (cap. III); las fiestas y sarao que se hicieron para la misma boda (cap. IV); se da noticia de los seis hijos que tuvieron («Juanete de pies, Martinete de gorras, Clemente de piedad, Marta de forro, Marina de playa, Margarita de nácar», f. 181r) y de sus andanzas por el mundo (cap. V); para terminar contando las enfermedades que tuvo el monstruo, cómo al final «se quedó muerto de risa» (f. 183v) y cómo se le hizo un «oficio mecánico» para su funeral (cap. VI); el último capítulo cierra la crónica de este estrafalario personaje de entremés o de comedia burlesca con un absurdo epitafio y unos «versos de artillería» compuestos e impresos por el monstruo imaginado («Eco a las letras del A.B.C. Coloquio, en el cual se le pregunta al Eco una razón, y responde a ella con una letra del A.B.C.»). Pese a las apariencias, este juguete intrascendente, donde el sabio glosador de los enigmáticos mensajes divinos se convierte en un hábil prestidigitador de vocablos, se ha de juzgar como el ideal reverso de la producción seria de Ledesma, según se verá a continuación.

3 Romancero/Y MONSTRO / imaginado. / COMPVESTo por Alon-/so de Ledesma. / Dirigido A PEDRo DE / Tapia, del Consejo Real, y de / la general, y suprema / Inquisicion. / Año [grabado] 1615. / Con PRIVILEGIo. / En Madrid, por la viuda de Alon- / so Martin. / _ _ A costa de Alonso Perez. Mercader de Libros; 7 folios preliminares con signaturas $\left[\mathrm{q}_{2}\right] ;\left[\mathrm{q}_{3}+5\right]+187$ folios numerados en el recto. Utilizo el ejemplar R/6303 (R.MICRO/9162) de la BNE. La Chrónica se sitúa entre los ff. 174r y 187r, bajo el rótulo «Burlas en equívocos, compuestas por Alonso de Ledesma». Se hicieron otras ediciones de la obra, cuyos ejemplares se conservan asimismo en la BNE: Lérida, Luis Manescal, 1616; Madrid, por la viuda de Alonso Martín, 1616; Barcelona, Sebastián de Cormellas, 1616. Espero editar pronto la obra en cuestión.

$4 \quad$ La portada reza así: «Chronica del Monstro / imaginado / Compuesta por Marcos / de Ventanas. / Dirigida a Madama Ana / de Tapices. / Señora de los Estados / de Figones. / Impresa en Corte / De cuchillo. / Con licencia del Ordinario / de mujer. / Véndese en casa de Tomé / de Portugal». Véase también el prólogo de burlas: «Este librillo de tripera (ocioso lector de artes) te saco a luz de linterna. Cuenta sus hojas de espada, mira sus capítulos de provincia, lee sus escritos de melón, nota sus cotas de malla, pasa su tabla de manteles, y acepta este don de la cartuja. Vale. Lo que tú quisieres» (f. 174v). Aquí y en las trascripciones sucesivas, he modernizado la grafía, regularizado la acentuación y el uso de mayúsculas según las normas de la RAE, e introducido una puntuación interpretativa; incluyo en el texto, entre paréntesis, el número del folio donde se hallan las distintas referencias. 
Empecemos por subrayar que esta obrita festiva es todo un síntoma del arte manierista, con su profunda atracción por lo monstruoso, lo feo, deforme y grotesco, con su refinado equilibrismo de elementos dispares y contradictorios, donde se sacrifican a menudo las reglas aristotélicas, que prescribían únicamente la imitación de lo bello, perfecto, armónico y verosímil, en aras de la libre invención y creación. Gracias a ello, el arte puede reproducir la suma belleza y variedad de la Naturaleza, donde caben lo maravilloso, lo prodigioso y lo excéntrico, o fabricar artilugios más curiosos, raros y espectaculares que la Naturaleza misma para sorprender y asombrar al público de oyentes/lectores o asistentes a fiestas públicas o particulares. La obrita de Alonso de Ledesma se inserta magistralmente en un texto cultural barroco donde seres monstruosos y deformes protagonizan no solo obras literarias celebérrimas — Los sueños (Quevedo 1991), el Criticón (Gracián 1990), La vida es sueño (Calderón 1991), El diablo cojuelo (Vélez de Guevara 2001), la Fábula de Polifemo y Galatea (Góngora 1990), por citar solo algunassino que aparecen en los tratados de alquimistas, filósofos naturales y teólogos, que se interrogan sobre su significación en el plan divino de la creación, o pueblan las curiosas relaciones de historiadores y geógrafos antiguos y modernos, y por último invaden las relaciones de sucesos, los avisos de forasteros, las cartas impresas y pliegos sueltos de la época donde se da noticia del nacimiento de criaturas monstruosas. El monstruo ensancha los límites de lo verosímil y pone de manifiesto la inadecuación de rígidas taxonomías y del lenguaje para representar todo lo existente:

El monstruo no es parte del alfabeto natural o lógico, sino de la crisis de ese alfabeto, que carece de referentes, que funciona como signo enigmático, desconocido. Puede, por eso, ser un divertimiento de la naturaleza (lusus naturae) o una palabra fracturada, pero la curiosidad por leerlo y descifrarlo es más grande, y se interpreta como objeto sensible, como fenómeno insólito que es también una noticia asombrosa e inesperada acerca de la misma naturaleza (Río Parra 2003: 17-18).

Según Río Parra (2003: 44-45), en el siglo XVII, a diferencia de épocas anteriores, conviven múltiples teorías, a veces contradictorias entre sí, para explicar lo monstruoso, recurriendo a varias disciplinas para clasificar y catalogar el fenómeno (astrología, zoología, medicina, biología, teología, filosofía, etc., etc.), y evidenciándose asimismo esa tendencia al pluriperspectivismo y a la proliferación y acumulación de «signos», enunciados lingüísticos y objetos sensibles que se encuentra no solo en el arte plástico barroco, con las decoraciones grutescas y las anamorfosis, sino también en los textos literarios, especialmente los adscritos al género de la «novela corta». Me refiero, en primer lugar, a su marcada estructura laberíntica y tortuosa, a la coexistencia de múltiples narradores y distintos puntos de vista, a la duplicación y amplificación de recursos retóricos entre marco 
y relatos secundarios; y por otro, a la naturaleza ambigua y contradictoria de por sí de la pasión amorosa, que es el móvil primero de toda su peripecia. Y dentro del pluriperspectivismo barroco cabe también la paradójica actitud de los grandes novellieri como Lope de Vega, que, en los prólogos o en las irónicas digresiones intercaladas a lo largo de los relatos, finge adecuarse a los preceptos teóricos para luego desmentirlos en la práctica del novelar (Pabst 1972: 9-20), porque «la novela appare marcata fin dal suo esordio dalla "coscienza infelice" della produzione di intrattenimento, che debe essere riscattata o con la sua "utilità", in quanto "esemplare", o con il vantato inserimento in una tradizione, cui la menzione di Aristotele aggiungerà nuova dignità» (Vega 1991: 13).

Si lo monstruoso es lo anormal, lo raro y lo marginal, y asimismo lo que se compone de elementos distintos y heterogéneos entre sí, la novela desde sus inicios se configura como género «monstruoso», sea porque las poéticas clásicas de Aristóteles y Horacio no se preocuparon de establecer sus leyes formales, sea porque en la novelística medieval se dio tal multiplicidad de intersecciones entre géneros literarios distintos que resulta «imposible diferenciar y extraer a la "novela corta" como forma "literaria especial"» (Pabst 1972: 51). Lope era muy consciente de ello en 1624, cuando aboga por la libertad creativa frente a la norma para complacer el «monstruoso» gusto de un público plural, ratificando, de ese modo, la condición fronteriza de la novela corta barroca:

[...] Que en este género de escritura ha de haber una oficina de cuanto se viniere a la pluma sin disgusto de los oídos, aunque lo sea de los preceptos; porque, ya de cosas altas, ya de humildes, ya de episodios y paréntesis, ya de historias, ya de fábulas, ya de reprensiones y ejemplos, ya de versos y lugares de autores, pienso valerme, para que ni sea tan grave el estilo que canse a los que no saben, ni tan desnudo de algún arte que le remitan al polvo los que entienden. Demás que yo he pensado que tienen las novelas los mismos preceptos que las comedias, cuyo fin es haber dado su autor contento y gusto al pueblo, aunque se ahorque el arte, y esto, aunque va dicho al descuido, fue opinión de Aristóteles (Vega 1991: 170)5 .

En 1615 Ledesma parece tener una similar percepción de las fronteras fluctuantes de la novela corta con otros géneros colindantes y asume una parecida actitud de «enmascaramiento» de la infracción de la norma poética dentro de la óptica transgresiva carnavalesca, donde son lícitos los caprichos de la fantasía para honesta recreación, según declara en el prólogo «de veras»:

Este juguete de equívocos (sujeto proprio de risa) hice unas carnestolendas para

5 No considero oportuno recoger aquí la bibliografía, muy extensa, sobre la utilización de la categoría estética de lo monstruoso en época barroca, remito solo a una de las contribuciones más recientes sobre el tema (Rabell 2012). 
honesta recreación, el cual imprimo entre cosas de veras, más por gusto de amigos que voluntad propia, y así, ¡oh convidado mío!, si en el banquete que te doy no te pareciere plato de sustancia, advierte que no te le sirvo a la mesa por manjar que te satisfaga, sino por cogollo de lechuga que te refresque. Vale (f. 174r).

En efecto, la naturaleza «monstruosa» de esta «ensalada de equívocos», como la llamó Chevalier (1992: 74), se evidencia no solo en el título paradójico de por sí, al yuxtaponer géneros literarios tan disímiles y heterogéneos como la crónica (es decir, narratio rei gestae / historias) y ficciones, frutos de la imaginación ( $f a-$ bulae), sino también en la proliferación desmesurada de la dilogía, que provoca desarmonía y desproporción en el estilo, y causa en el lector una cierta sensación de cansancio. En la urdimbre del texto, la dilogía, reseñada por Serra (2000: $367-$ 386) entre los «artificios de multiplicación», se presenta casi siempre dentro de sintagmas nominales de especificación (sustantivo + de + sustantivo), la mayoría de las veces simplemente yuxtapuestos y separados por comas; la sensación de hallarse ante una retahíla casi infinita, pero fragmentada y disgregada de vocablos, a modo de rêverie onírica, se compensa por el hecho de que esta unidad básica de significación «asombrosa» viene insertándose en esquemas y secuencias narrativas ordenadas, que convierten los partos inverosímiles de la fantasía en algo plausible dentro del terreno de la ficción.

Bien mirada, también la estructuración de la materia diegética es híbrida, mestizada, en fin, «equívoca», porque obedece a varios paradigmas compositivos, todos vinculados de algún modo a las fiestas carnavalescas o a las fiestas burlescas cortesanas. De hecho, en este singular micro género de la novelística barroca, ideado por Ledesma e identificado por la crítica como el «retrato del monstruo» (Chevalier 1992: 147 y Periñán 1979: 68) ${ }^{6}$, se puede rastrear claramente la influencia del motejar cortesano renacentista, con su caricatura a base de apodos, del disparate tanto poético como dramático, con sus variados juguetes de ingenio (el inventario heteróclito, los linajes de burla, el desfile incoherente de personajes, el delirio de los adynata, la tautológica perogrullada), el influjo de festejos callejeros como mascaradas o mojigangas con sus monstruos, gigantones y «figuras de capricho», y de diversiones cortesanas como bodas, banquetes, sortijas, justas, o académicas, con sus vejámenes y pullas satíricas. E incluso podemos hallar patentes reminiscencias del Quijote, con sus «relatos curriculares» (Moner 1986), y de los textos entremesiles a él vinculados, mientras que el retrato de los personajes secundarios, como los hijos del monstruo, exhibe un claro parecido con los protagonistas o personajes secundarios de la

6 Entre los antecedentes renacentistas del «retrato del monstruo», Antonio Paz y Meliá ha identificado una anónima «Carta del monstruo satírico de la lengua española», en equívocos burlescos (Río Parra 2003: 202). 
novela picaresca ${ }^{7}$. Asimismo la crónica disparatada de Ledesma se puede leer como una evidente parodia de las biografías y semblanzas de los claros varones de Castilla y de las Relaciones verdaderas que, a lo largo del siglo XVII, dieron noticia de los monstruos (de su crianza, hazañas y fuerzas sobrenaturales).

Según mi parecer, nos encontramos con una pequeña joya que muestra, en el breve espacio de unas cuantas páginas, el rico entramado de fuentes y paradigmas literarios que cobrará auge con las obras esclarecidas de Cervantes, Castillo Solórzano, Zayas, Tirso, y secundariamente será aprovechado por todos los novelistas menores, convirtiendo en realidad la rica polisemia encerrada en la palabra italiana nuovo (s. XIV):

El latín novum y el italiano antiguo nuovo abarcan toda una escala de tonos y gradaciones cuyo brote más alto está representado, quizás, por la Vita Nova de Dante, mientras que los escalones más bajos aportan de vez en cuando un sentido secundario al literario de novella, como por ejemplo el de lo sorprendente o curioso, el de lo cómico o chistoso, el de lo divertido o lo burlesco, el de lo picaresco o bufonesco, de lo imaginativo o incluso de lo mentiroso (Pabst 1972: 46-47)8.

Finalmente, señalemos que el cuento de Ledesma tuvo imitadores, si bien marginales dentro de la larga historia de la novela corta: en 1640 el sevillano Francisco Navarrete y Ribera compuso una Novela del caballero invisible, compuesta en equívocos burlescos, impresa en su Flor de Sainetes (Navarrete y Ribera 2001: 194-198).

Pasemos, ahora, a dar unas pequeñas muestras del peculiar estilo jocoso de la Chrónica del monstro imaginado. Quisiera empezar precisamente por la apertura del cuento, con la descripción física del monstruo: la enumeración de los rasgos físicos es muy pormenorizada, siguiendo muy de cerca los esquemas presentes en los tratados de fisiognómica de la época, y tal vez se inspire en la iconografía de algunos emblemas donde, para representar determinados vicios como, por ejemplo, la Gula, se retrataban hombres-monstruos con cuello largo de grulla (Río Parra 2003: 162-165):

En la Mancha de aceite, año de veinte de bolos por mayo de trepar, nació un monstro con dos cabezas, una de proceso y otra de ajos, y en ella sesos de olla, cascos de calabaza y pelo de pecho de parida. Dos caras, una de necesidad y otra de be-

\footnotetext{
Para ahondar en las posibles intersecciones de la novela de Ledesma con todos estos géneros literarios burlescos y jocosos ligados a la fiesta barroca, véanse Egido (1978), Huerta Calvo (2001), Colón Calderón (2001) y Navarro Durán (2004).

8 A propósito de la profunda y continuada influencia de los novellieri italianos sobre la novela corta española de los siglos XVI y XVII, habrá que mencionar el proyecto de investigación Pampinea y sus descendientes en la UCM de Madrid, cuyos primeros adelantos han sido publicados en un reciente volumen colectivo (Colón Calderón 2013).
} 
nevolencia, y en ellas ojos de puente, cejas de guitarra, pestañas de raso, orejas de mercader, boca de verano, dientes de sierra, muelas de barbero, lengua de agua, barba de ballena y mostachos de confitura. Dos cuellos, uno de sujeción y otro de cantimplora, garganta de música, nuez de especia, pechos de alcabala, espaldas de amigo, corazón de zanahoria y miembro de justicia. Cuatro brazos, dos de favor y dos de mar, y en ellos muñecas de Flandes, manos de papel, palmas de dátiles y uñas de dificultad. Cuatro piernas, dos de nuez y dos de sábana, y en ellas muslos de calzas, rodillas de fregar, canillas de redeña y pies de copla (f. 175r-v).

Aquí la dilogía desempeña un papel fundamental en la creación de la monstruosidad del protagonista, porque hace posible tanto la disgregación como la acumulación y asociación de elementos heterogéneos y disímiles, según una técnica de composición que recuerda a los retratos compuestos de Arcimboldo y a los seres monstruosos de Quevedo, aunque las imágenes visuales evocadas por la dilogía no lleguen a formar una figura definida como en el caso del famoso pintor italiano. Esto ocurre especialmente cuando al sentido referencial de una palabra dilógica se superpone el metafórico («boca de verano»), o cuando algunos modismos o frases hechas vehiculan, in absentia, un preciso sentido metafórico que explica una determinada asociación de vocablos, sin que medie entre ellos una dilogía propiamente dicha, como en el caso de «uñas de dificultad» o «espaldas de amigo» (respectivamente «tener uñas algo», «con uñas y dientes» o «tener las espaldas cubiertas/guardadas» o «echarse sobre las/sus espaldas algo», que es acción propia de amigos). Cabe notar, además, que algunas dilogías son de uso común y coloquial como «cabeza de ajo», «cascos de calabazas», «ojos de puente», «dientes de sierra», «lengua de agua», «piernas de nuez», mientras que otras, en cambio, resultarán más sorprendentes para el lector por utilizar una acepción más técnica-sectorial de la palabra bifronte, como en el caso de «cabeza de un proceso», «garganta de música», "pechos de alcabala» o «pierna de sábana». En todo caso, en el texto de Ledesma prima la intención lúdica sobre la alegórica, que prevalece en los cuadros de Arcimboldo, o sobre la satírica de la peculiar teratología quevedesca, donde algunos tipos humanos se transforman en trágicos y grotescos muñecos, mutilados, animalizados o cosificados, como la dueña Quintañona del Sueño de la Muerte (Levisi 1968: 223-225) ${ }^{9}$.

Veamos otro fragmento donde en «el reto de la dificultad vencida» se luce más el ingenio del autor, porque tendrá que describir movimiento y acción, como ocurre en la relación de las fiestas que hubo para la boda del monstruo:

En una plaza de oidor, adornada con varias sedas de zapatero, cercada de tres altos como brocado — en el primero había rejas de arado; en el segundo, ventanas de

9 Sobre la imaginería monstruosa de los Sueños de Quevedo, véase también Checa (1998: 197-203). 
narices; y en el tercero, corredores de lonja - se celebraron estas fiestas de guardar. El primer día hubo una justa de conciencia, en la cual salió el novio con unas armas de tumba, y sobre la cabeza una celada de enemigos y en el penacho muchas plumas de escribanos, el cual dio a los jueces esta letra:

Honor, y no precio busco, que no quiero mi desprecio si le gano con desprecio.

Justó el novio, a quien honraron con aplauso y dieron premio, diciéndole que para tal justador honra y provecho caben en un saco. Esta noche hubo sarao, donde la novia, al son de una ginebra de Saboya templada, con un cinco órdenes de frailes, salió a danzar una alta de estatura, una baja de rentas, una gallarda de talle, una morisca de ley, unas vacas de carnicería, un canario de jaula y un villano del Danubio. El segundo día salió el novio a correr una sortija de dedo, con librea morada y verde, morada de habitación y verde por madurar, el cual daba esta letra:
La letra para mi dama
es que la sustente y vista,
que es pagar a letra vista.

Acetaron esta letra las damas sobre sus galanes, pero ellos la protestaron a título de no poder pagalla (f. 179r-v).

En este caso, el lector entra a pie juntillas en el reino del absurdo y del disparate por medio de la dilogía: en unos casos, esta tiene un valor casi tautológico («alta de estatura», «gallarda de talle», «canario de jaula», «sortija de dedo», «morada de habitación y verde por madurar») que nos recuerda de cerca la perogrullada; en otras ocasiones, se hermana con otros artificios ludolingüísticos como la antanaclasis: en los versos cifrados de las empresas del monstruo se juega burlonamente con la polisemia de las palabras homónimas «desprecio», «letra», «vista». Una cierta sensación de tosco automatismo nos comunican, en cambio, otros sintagmas como «fiestas de guardar», donde se rompe la norma lingüística alterando simplemente el orden de los componentes de frases hechas («guardar las fiestas»); pese a ello, resultan perfectamente consecuentes con los dictados de la poética caótica del Carnaval, donde todo está dicho y hecho al revés.

Recapitulando, podemos afirmar que la «carnavalización del lenguaje», en palabras de Bajtín, que ilumina con el chispazo de la agudeza los recovecos oscuros del idioma, incita la complicidad del lector y aviva su entendimiento en el desciframiento del doble sentido, porque, si bien ocioso, este desea leer y saber. Según mi opinión, pese al marcado carácter festivo y regocijado del texto, no podemos descartar la hipótesis de que Ledesma se propusiera también una finalidad 
pedagógica con la edición de su juguete, intención que parece asomarse precisamente en el final de la obra, con la interpolación de los ficticios versos del monstruo imaginado. Su estructura, en forma de acertijo, se asemeja a la de un divertido ejercicio escolar de aprendizaje del abecedario, donde se juega con el doble sentido de palabras homófonas:

Eco, yo querría de ti todo el A.B.C. saber. $\mathrm{Di}$, ¿sabrasme responder cada letra de por sí?

En dos letras el sí va, pero más me lo acrisola; dime ¿cómo en una sola tu voz me responderá?

Aconséjame si iré a casar con cierta dama de limpia y honesta fama aunque en pobreza se ve.

Al que su nombre no sé, ¿cómo le podré llamar sin haberle de nombrar de «tú»» ni «vuestra merced»?

¿Y qué consejo daré al galán que quiera más, porque no se quede atrás por lo que yo me quedé?

A

B

C

D

(ff. $184 \mathrm{v}-185 \mathrm{r}$ )

Caben dos interpretaciones, a mi modo de ver, acerca del modo singular en que Ledesma decide despedirse de sus lectores: dentro del plano ficcional, estos versos son el legado del monstruo a la posteridad, en el que revela subrepticiamente el íntimo secreto de su existencia: fue una «fábula» (en el doble sentido de «cuento» deleitoso y «objeto de irrisión») ${ }^{10}$ compuesta de vocablos; dentro del plano metaficcional, en estas redondillas el autor descubre los ingredientes basilares de sus trucos y magias verbales: las letras del alfabeto. Pero hay más: es sabido que en la época el ars combinatoria con las letras del alfabeto tiene una precisa significación iniciática y órfica, por lo cual la Chrónica del monstro imaginado se sitúa dentro de un evidente continuum con la producción poética sagrada de Ledesma, como se había afirmado al inicio de estas breves páginas. A este propósito,

10 Dicc. Aut., III, 704b. 
quisiera recordar el libro Curiosa y oculta filosofia (Nieremberg 1643), que habla de mudanza, artificio, monstruos y maravillas de la naturaleza, donde se explica el conocido tópico, de derivación alquímico-cabalística, de un mundo-libro divino y laberíntico, lleno de símbolos y enigmas, que, si son correctamente descifrados, revelan el orden secreto del universo:

En ella este prolífico jesuita creía que el «mundo es un laberinto poético», escrito por Dios, en el «que por todas partes se lee y se dicta su Autor». El capítulo constituye una síntesis sobre el tema, que curiosamente poco tiene que ver con la idea de confusión que el laberinto acarreaba, sino con un mundo escrito por la mano divina y susceptible de ser descifrado con orden y concierto. [...] La historia del mundo como libro configura por sí misma otro libro de innumerables páginas simbólicas que lo convirtieron en tópico universal. En ellas brilla con particular relieve la idea de un mundo-libro, ordenado y armónico por la escritura divina, que, en definitiva, es siempre el modelo a seguir por todo autor que aspire a reflejarla (Egido 2014: 150-151) ${ }^{11}$.

Para un hombre como Ledesma, la enseñanza del alfabeto se configura, pues, como un ineludible y grave cometido espiritual, por el cual se pasa de mano en mano el ovillo para salir tanto de laberintos verbales y visuales artificiosos como reales, puesto que, para la doctrina católica, la vida terrenal es también camino laberíntico acechado por el pecado y la muerte.

Para terminar, cabe un última reflexión sobre el final de este lindo cuento: con la invención de la imprenta las letras del alfabeto cobraron tanta relevancia como objetos independientes y autónomos, que dieron pie a juegos de todo tipo en los libros de antaño (Bolzoni 1995: 90 y ss.); rendir homenaje a Gutenberg, que hizo posible la perpetuación de la novela corta barroca a lo largo de los siglos, efectivamente no estaba de más.

Recibido: 14/09/2014

Aceptado: 15/10/2014

\section{OBRAS CITADAS}

Bolzoni, Lina (1995). La stanza della memoria. Modelli letterari e iconografici nell'età della stampa. Turín: Einaudi.

Calderón de la Barca, Pedro (1991). La vida es sueño. Ciriaco Morón (ed.), 18 a ed. Madrid: Cátedra.

CARA, Giovanni (2001). Il «vejamen» in Spagna. Juicio y regocijo letterario nella prima metà del XVII secolo. Roma: Bulzoni.

11 La idea del poeta/escritor como segundo Dios, artífice de enrevesados laberintos narrativos, subyace también en la escritura de novelas con lipograma (Gallo 2003: 7-27). 
CHECA, Jorge (1998). «Figuraciones de lo monstruoso: Quevedo y Gracián». La Perinola, 2, pp. 195-211.

Chevalier, Maxime (1992). Quevedo y su tiempo: la agudeza verbal. Barcelona: Crítica.

Colón CAlderón, Isabel et alii (eds.) (2013). Los viajes de Pampinea. «Novella» y novela española en los Siglos de Oro. Madrid: Sial Ediciones.

(2001). «Humor y fábulas burlescas en la novela cortesana». En Javier Huerta Calvo, Emilio Peral Vega y Jesús Ponce Cárdenas (eds.), Tiempo de burlas. En torno a la literatura burlesca del Siglo de Oro. Madrid: Verbum, pp. 91-108.

D’Ors, Miguel (1974). Vida y poesía de Alonso de Ledesma. Contribución al estudio del conceptismo español. Pamplona: Ediciones Universidad de Navarra.

EGIDO, Aurora (1978). «Retablo carnavalesco del Buscón don Pablos: Artículo-reseña». Hispanic Review, 46, 2, pp. 173-197.

(2014). La búsqueda de la inmortalidad en las obras de Baltasar Gracián, discurso leído el día 8 de junio de 2014 por la Excma. Sra. Da Aurora Egido y contestación del Excmo. Sr. D. Pere Gimferrer, Madrid/Zaragoza: Real Academia EspañolaInstitución «Fernando el Católico».

Gallo, Antonella (2003). Virtuosismi retorici barocchi: novelle con lipogramma. Florencia: Alinea.

Góngora, Luis de (1990). Fábula de Polifemo y Galatea. Alexander P. Parker (ed.), $4^{\mathrm{a}}$ ed. Madrid: Cátedra.

Gracián, Baltasar (1987). Agudeza y arte de ingenio. Evaristo Correa Calderón (ed.), 2 vols. Madrid: Castalia.

Gracián, Baltasar (1990). El Criticón. Santos Alonso (ed.), $4^{\mathrm{a}}$ ed. Madrid: Cátedra.

Huerta Calvo, Javier (2001). «Los espejos de la burla. Raíces de la comedia burlesca». En Javier Huerta Calvo, Emilio Peral Vega y Jesús Ponce Cárdenas (eds.), Tiempo de burlas. En torno a la literatura burlesca del Siglo de Oro. Madrid: Verbum, pp. 161-176.

Ledesma, Alonso (1602). Conceptos espirituales. Madrid: Imprenta Real, por Juan Flamenco, en casa de P. de la Torre.

(1607). Segunda parte de los Conceptos espirituales, y morales. Barcelona: Imprenta de Jaime Cendrat, a costa de Hierónimo Margarit.

(1611). Juegos de Noche Buena, moralizados a la vida de Christo, martirio de Santos, y reformación de costumbres, con unas enigmas hechas para honesta recreación. Madrid: Alonso Martín, a costa de Alonso Pérez.

(1612). Tercera parte de Conceptos espirituales, con las obras hechas a la Beatificación del glorioso Patriarca Ignacio de Loyola ...para el Colegio de la ciudad de Segovia. Lérida: Imprenta Marescal.

(1615). Romancero y monstro imaginado. Madrid: Viuda de Alonso Martín.

(1625). Epigramas y hieroglificos, a la vida de Christo, festividades de nuestra Señora, excelencias de santos, y grandezas de Segovia. Madrid: Juan González, a costa de Lucas Ramírez.

(1969). Conceptos espirituales. Eduardo Juliá Martínez (ed.). Madrid: CSIC.

(1978). Conceptos espirituales y morales. Francisco Almagro (ed.). Madrid: Editora Nacional. 
LEVISI, Margarita (1968). «Las figuras compuestas en Arcimboldo y Quevedo». Comparative Literature, 20, pp. 217-235.

MONER, Michel (1986). «El "relato curricular": algunos aspectos de la narrativa cervantina». En Formas breves del relato: Coloquio Casa de Velázquez-Departamento de Literatura Española de la Universidad de Zaragoza (Madrid, febrero de 1985). Zaragoza-Madrid: Universidad de Zaragoza-Casa de Velázquez, pp. 167-176.

Navarrete y Ribera, Francisco (2001). Flor de sainetes. Antonella Gallo (ed.). Florencia: Alinea.

Navarro DurÁn, Rosa (2004). «El entremés, espacio para la transgresión. Los disparates de "La Infanta Palancona"». En Olivia Navarro y Antonio A. Serrano Agulló (coords.), En torno al teatro del Siglo de Oro: XVI-XVII Jornadas de Teatro del Siglo de Oro. Almería: Instituto de Estudios Almerienses, pp. 101-115.

Nieremberg, Juan Eusebio (1643). Curiosa y oculta filosofí. Primera y segunda parte de las maravillas de la naturaleza examinadas en varias cuestiones naturales. Contiene historias muy notables. Averíguanse secretos y problemas de la naturaleza con Filosofía nueva. Madrid: Imprenta Real.

PABST, Walter (1972). La novela corta en la teoría y en la creación literaria. Rafael de la Vega (trad.). Madrid: Gredos.

Periñán, Blanca (1979). Poeta ludens. Disparate, perqué y chiste en los siglos XVI y XVII. Estudio y textos. Pisa: Giardini Editori.

Quevedo, Francisco de (1991). Los sueños. Ignacio Arellano (ed.). Madrid: Cátedra.

Rabell, Carmen R. (2013). «Lope de Vega: política y poética de lo monstruoso». En Alain Bègue y Emma Herrán Alonso (dir.), Pictavia aurea. Actas del IX Congreso de la Asociación Internacional Siglo de Oro (Poitiers, 11-15 de julio de 2011). Toulouse: Presses Universitaires du Mirail, pp. 1065-1074.

Río PARRA, Elena del (2003). Una era de monstruos. Representaciones de lo deforme en el Siglo de Oro español. Madrid/Frankfurt am Main: Iberoamericana - Vervuert.

RodríGueZ DE LA Flor, Fernando (1982). «"Pictapoesis”: un sermón en jeroglíficos, dedicado por Alonso de Ledesma a las fiestas de beatificación de San Ignacio, en 1610». Anales de Literatura Española, 1, pp. 119-133.

SAlazar, Alonso (1610). Fiestas que hizo el insigne Colegio de la Compañía de Jesús de Salamanca a la Beatificación del glorioso Patriarca S. Ignacio de Loyola ... por Alonso de Salazar. Salamanca: Viuda de Artus Taberniel.

SERRA, Màrius (2000). Verbalia. Juegos de palabras y esfuerzos del ingenio literario. $1^{\mathrm{a}} \mathrm{ed}$. Barcelona: Península.

VegA, Lope de (1991). Novelle per Marzia Leonarda. Maria Grazia Profeti (ed.), Paola Ambrosi (trad.), $1^{\text {a }}$ ed.Venecia: Marsilio.

Vélez de Guevara, Luis de (2001). El diablo cojuelo. Enrique Rodríguez Cepeda (ed.), $4^{\mathrm{a}}$ ed. Madrid: Cátedra.

VIndel, Francisco (1941). Las treinta casualidades que hacen sea Alonso de Ledesma el autor del "Falso Quijote”. Madrid: s.e. 


\section{(2)}

FABULACIONES EN EQUíVOCOS BURLESCOS: LA CHRÓNICA DEL MONSTRO IMAGINADO (1615)

de Alonso de Ledesma y novela corta barroca

Resumen: En 1615 el jesuita Alonso de Ledesma edita un cuento en equívocos burlescos, La Chrónica del monstro imaginado, que pone en evidencia, por un lado, la consustancial «monstruosidad» y heterogeneidad de la novela corta barroca, y por otro, su profunda hibridación con prácticas festivas carnavalescas y las artes visuales manieristas. En este prodigio o maravilla de la agudeza conceptista, que dejará huella en Quevedo y en Vélez de Guevara, luce el ingenio de su autor: a través de múltiples artificios ludolingüísticos divierte y advierte al lector, el cual intuye, detrás de las disparatadas piruetas verbales del cuento, el simulacro del laberíntico mundo-libro escrito por Dios.

Palabras Clave: Novela corta, Alonso de Ledesma, Equívocos burlescos, Monstruosidad, Arte manierista.

\section{Fabulous Stories with Burlesque Puns: the Chrónica del monstro imaginado (1615) by Alonso de LEDESMa and Baroque SHORT NoVEL}

ABSTRACT: In 1615 the jesuit Alonso de Ledesma publishes a short novel in a satirical-burlesque style, plenty of puns and wordplays, la Chrónica del monstro imaginado, which points out on the one hand the consubstantial "monstrosity" and heterogeneity of the baroque short novel, on the other hand its deep hybridization with carnival festivals and rituals as well as baroque visual arts. In this prodigious and wonderful exemplification of baroque witticism, which is going to have a deep influence both on Quevedo and Vélez de Guevara, the author shows off his brilliant talent for different wordplays through which he amuses and warns the reader, who is able to perceive, behind the nonsense verbal pirouettes of the tale, the simulacrum of the tortuous world, a world book-shaped, created and written by God.

Keywords: Short Novel, Alonso de Ledesma, Burlesque Puns, Monstrosity, Baroque Art. 
Evangelina Rodríguez Cuadros (Universitat de València)

Novela cortesana, novela barroca, novela corta: de la incertidumbre al canon .9

Mita Valvassori (Universidad de Los Lagos)

El modelo narrativo del Decamerón en la Edad de Oro: una vieja historia .21

Antonio Gargano (Università degli Studi di Napoli Federico II)

«Difficile est proprie communia dicere»: el género de la novella entre

Boccaccio y Cervantes

Guillermo Carrascón (Università degli Studi di Torino)

Apuntes para un estudio de la presencia de Bandello en la

novela corta del siglo XVII

Leonardo Coppola (Università degli Studi «G. d'Annunzio» di Chieti-Pescara)

La proyección de Straparola en la novela española del Siglo de Oro desde una perspectiva editorial

Mireia Aldomì García

Didactismo, género literario y lector en Giraldi Cinzio.

María Jesús Zamora (Universidad Autónoma de Madrid)

«...En tiempo menos discreto que el de agora, aunque de hombres más sabios, se

Ilamaban a las novelas cuentos». La novela corta y el cuento en el Siglo de Oro.....109

Marcial Rubio (Università degli Studi «G. d'Annunzio» di Chieti-Pescara)

La contribución de Cervantes a la novela barroca: la ejemplaridad. .125

PIERRe Darnis (Université Bordeaux Montaigne)

La fuerza de la sangre, La ilustre fregona $y$ Las dos doncellas: ¿tres tipos

folclóricos?

María Soledad ArRedondo (Universidad Complutense de Madrid)

De La gitanilla $a$ La sabia Flora malsabidilla. El género, el personaje

y el matrimonio

Antonella Gallo (Università degli Studi di Verona)

Fabulaciones en equívocos burlescos: la Chrónica del monstro imaginado (1615)

de Alonso de Ledesma y novela corta barroca

David GonZález Ramírez (Universidad de Málaga)

El filósofo del aldea (1625) de Baltasar Mateo Velázquez: recepción textual

e hipótesis autorial.

Jonathan BRAdBury (University of Exeter)

La narrativa breve en la miscelánea del siglo XVII 
Cristina Castillo Martínez (Universidad de Jaén)

«La fuente del desengaño»: de las Noches de invierno de Eslava a la Tercera

Diana de Tejeda.

María Zerari (Université Paris-Sorbonne, CLEA)

Furor in fabula: La cruel aragonesa de Castillo Solórzano (o de la dama monstruo).. 241

Giulia Giorgi (Università degli Studi di Ferrara)

Alonso de Castillo Solórzano reescritor de sí mismo: algunas notas sobre los

Escarmientos de amor moralizados y el Lisardo enamorado .257

Angela Fabris (Alpen-Adria-Universität Klagenfurt)

El diálogo con el público y los espacios reales y de maravilla en

Casos prodigiosos y cueva encantada de Juan de Piña .267

María Rocío LePe García (IES San Sebastián, Huelva)

La traducción inglesa de Hipólito y Aminta: una adaptación

con fines comerciales 281

Andrea Bresadola (Università degli Studi di Udine)

La novela española en la Italia del siglo XVII: el caso de Il Feniso

de Francisco de Quintana

José Teruel (Universidad Autónoma de Madrid)

El triunfo del Desengaño. Marco y desengaño postrero de la Parte segunda

del Sarao y entretenimiento honesto, de María de Zayas

Nieves Romero-Díaz (Mount Holyoke College)

Lecturas alternativas en la Novela del fin bueno en mal principio

de doña Ana Francisca Abarca de Bolea.

Shifra Armon (University of Florida)

Compromiso y distanciamiento en La Venus de Ferrara

de Mariana de Carvajal Saavedra

Mechthild Albert (Rheinische Friedrich-Wilhelms-Universität Bonn)

Las "noches": un subgénero novelístico en perspectiva comparada.... .365

Fernando Copello Jouanchin (Université du Maine, Le Mans)

El mueble en la novela corta del Siglo de Oro: algunas reflexiones

en torno a la cama

Ilaria Resta (Università del Salento):

De la novella al entremés pasando por la novela corta: reescrituras del cuento

La gara delle tre mogli del Cieco di Ferrara. 


\section{EDAD DE ORO}

Revista de Filología Hispánica XXXIII

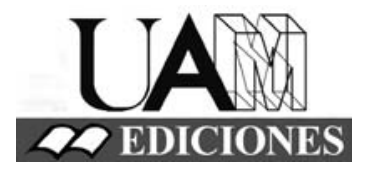




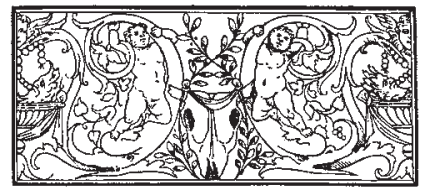

\section{Edad de Oro. Revista de Filología Hispánica}

ISSN: 0212-0429

Dirección:

Teodosio Fernández

Secretaría y edición:

José Ramón Trujillo

Coordinador del volumen XXXIII:

Rafael Bonilla Cerezo

Comité científico internacional:

Carlos Alvar (Univ. de Ginebra)

Ignacio Arellano (Univ. de Navarra)

Javier Blasco (Univ. de Valladolid)

Alberto Blecua (UAB)

Jean Canavaggio (Univ. de París X)

Laura Dolfi (Univ. de Turín)

Aurora Egido (Univ. de Zaragoza)

Víctor García de la Concha (RAE)

Luciano García Lorenzo (CSIC)

Joaquín González Cuenca (Univ. de Castilla-

La Mancha)

Agustín de La Granja (Univ. de Granada)

Begoña López Bueno (Univ. de Sevilla)

Michel Moner (Univ. de Toulouse III)

Joan Oleza (Univ. de Valencia)

Alfonso Rey (Univ. de Santiago)

Lina Rodríguez Cacho (Univ. de Salamanca)

Leonardo Romero Tobar (Univ. de Zaragoza)

Aldo Ruffinatto (Univ. de Turín)

Lía Schwartz (City University of New York)
Redacción y admisión de originales:

Teodosio Fernández

Edad de Oro

Departamento de Filología Española

Universidad Autónoma de Madrid

28049 Madrid (España)

Tfno.: +0034 914974090

correo: teodosio.fernandez@uam.es

Distribución, suscripción y venta:

Servicio de Publicaciones de la UAM

Universidad Autónoma de Madrid

28049 Madrid (España)

Intercambio de publicaciones:

Biblioteca de la Facultad de Filosofía y

Letras (UAM)

Universidad Autónoma de Madrid

28049 Madrid (España)

Han colaborado en este volumen:

Departamento de Filología Española (UAM)

Facultad de Filosofía y Letras (UAM)

Proyecto I+D FFI2013-41264-P La novela

corta del siglo XVII: estudio y edición (y II)

Edad de Oro se recoge en las siguientes bases de datos: SCOPUS, MLA Database, HLAS, Latindex, PIO-Periodical Content Index, ISOC, Dialnet, MIAR, ERIH, DICE, Sumaris CBUC, Ulrich's. Se encuentra evaluada en CIRC: A; INRECH: primer cuartil, posición 6 de 50; MIAR difusión ICDS live: 9.977; SCImago Journal \& Country Rank: H Index 2, SJR 0,101, Q4; RESH índice de impacto: 0.162; ERIH: A INT1; Carhus Plus+: B. 